\title{
EDITORIAL
}

\section{Thinking Ahead Towards Converging Perspectives}

\author{
Kanchan Chopra $^{1}$
}

As this issue of the Journal is published, at this crucial juncture in history, when the global pandemic seems to be relentless, the good news is that more holistic thinking and action on environmental issues is emerging all around. The agenda of humanity's need to deal with climate change immediately has come to the fore. Also, and importantly, the International Panel for Climate Change (IPCC) and the International Platform for Biodiversity and Ecosystem Services (IPBES), the two inter-governmental agencies charged with the responsibility of designing action on climate change, biodiversity, and ecosystem services, joined hands to publish a Report (in June 2021) on the synergies and trade-offs between actions on climate change and biodiversity. Even more significantly, perhaps, the UNDP Report (2020), for the first time, compiled a country-wise human development index adjusted for planetary impact called the Planetary Human Development Index (PHDI). This brings the planetary impact of development into focus in a big way. In India, the Biodiversity Collaborative, a major initiative supported by the government, brought together a network of institutions and individuals to promote biodiversity research and conservation to enhance human well-being. A National Coalition for Natural Farming is due to celebrate the first year of its existence.

\footnotetext{
${ }^{1}$ Co-ordinating Editor (2020-21), Former Director, and Professor, Institute of Economic Growth, University of Delhi, New Delhi-110007; choprakanchan14@gmail.com.

Copyright (C) Chopra 2021. Released under Creative Commons Attribution-NonCommercial 4.0 International licence (CC BY-NC 4.0) by the author.

Published by Indian Society for Ecological Economics (INSEE), c/o Institute of Economic Growth, University Enclave, North Campus, Delhi 110007.

ISSN: 2581-6152 (print); 2581-6101 (web).

DOI: https://doi.org/10.37773/ees.v4i2.524
} 
In a small though significant manner, the ground covered by the contributions to this issue resonate with these developments, both by way of reflections on some and provision of conceptual and policy underpinnings for others.

A seminal event in early 2021 was the publication of a global review led by Professor Partha Dasgupta titled The Economics of Biodiversity. This review reiterates that we are part of Nature; human beings as well as the flora and fauna are embedded in it. Through a well-documented and succinctly explained set of arguments, this report points out the practical manner in which we can guide human activity to remain limited to the "safe operating space" within the bounds of nature.

This issue carries two commentaries on The Dasgupta Review-one offers an ecologist's perspective and the other an economist's. While taking due note of the depth and reach of the recommendations, both feel that the Review could have paid more attention to pathways for institutional change and the role of bio-centric approaches, political ecology, and other new approaches to environmental problems.

The two thematic essays in this issue exemplify different perspectives towards environmental policy. One of them, in the tradition of environmental economics, reviews the available information and identifies gaps that thwart the realization of ambient standards of environmental quality. Using air pollution in Delhi as an example, it provides a discussion on how to use available economic estimates for designing and using economic instruments such as pollution taxes and pollution permits in addition to using command-and-control approaches.

The second thematic essay provides an overview of the literature on sociometabolic research. Changes in bio-physical stocks and flows over time measure the impact of human activity on the environment. As development in the conventional sense (of production of more goods and services) takes place, the social metabolism of the economy as measured by these changes is altered. For example, for the first time in human history, more than 100 billion tonnes of materials enter the global economy every year, of which only about $8 \%$ is recycled, creating an enormous "circularity gap". This perspective encourages us to use physical flows to study the impact on the environment.

One of the research papers provides a partial application of a material export-import analysis of the Nicobar Islands. The authors study physical export-import flows in the archipelago to reflect on the social, economic, and ecological impact of the tsunami of 2004 and the subsequent process of recovery. This literature pinpoints what we are missing when we measure 
change only through monetary values. However, the question that remains unanswered is this: how does it provide direction to policy-makers? And how will it translate into the kind of change we need in human behaviour?

As a counterfoil to the above, two research papers study individual and household behaviour in response to new technologies or new ways of packaging them. One looks at the solar energy option and asks: if a solar microgrid is introduced in a region as an alternative servicing system, how will it impact the demand for solar appliances? The total impact, sometimes referred to as "the frontier rebound effect," is investigated in the context of a rural community in Rajasthan. On a similar note, another paper studies farmers' decisions with regard to the adoption of on-farm conservation measures and finds that the existence or otherwise of community-level measures has a significant effect on individual decisions. So do the decisions taken by others in the village.

In terms of policy design, both these papers provide pointers towards a combination of strategies. In one case, a lower price for solar power needs to be coupled with a different packaging of technology. In the second, the nature of individual behaviour as nested in collective behaviour is highlighted. These in-depth, empirical explorations in disparate settings offer us clues on how to enable change.

In summary, this issue of the Journal reflects on and presents diverse approaches to the environmental, indeed existential, dilemmas that humanity now encounters. In the final analysis, each of these approaches throws light, through alternative lenses, on the same reality. How can we use them to converge on pathways for a nature-friendly future? That is the question that needs to be addressed now.

And finally, the Editorial Board of EES and the Executive Committee of INSEE would like to express their grateful thanks to the Foundation for Ecological Security for a generous grant that has supported the publication of the two issues of this volume of the Journal. 